\title{
Exploration and Thinking on the Development of Sports Lottery Market in County Area of Suzhou
}

\author{
Yan Peng, Zhangzhi Ge \\ School of Public Affairs, University of Science and Technology of China, Hefei, China \\ Email: gezhangzhi2008@163.com
}

How to cite this paper: Peng, Y. and Ge, Z.Z. (2016) Exploration and Thinking on the Development of Sports Lottery Market in County Area of Suzhou. Open Journal ot Business and Management, 4, 686-695. http://dx.doi.org/10.4236/ojbm.2016.44068

Received: August 23, 2016

Accepted: September 13, 2016

Published: September 16, 2016

Copyright $\odot 2016$ by authors and Scientific Research Publishing Inc. This work is licensed under the Creative Commons Attribution International License (CC BY 4.0). http://creativecommons.org/licenses/by/4.0/

\begin{abstract}
Lottery has an irresistible charm and its issuance becomes a rational choice to make up for the lack of national financial investment in social welfare undertakings. Based on the current situation of China's lottery economy, this paper firstly analyzes three major backgrounds for Suzhou developing the county sports lottery market, which is clear policy direction, a solid foundation of the county economy and effective sports organizations. And then it reveals Suzhou's practical exploration and achieving results of its county sports lottery market from the institutional mechanisms, personnel construction, sales channels and brand building. Finally, this paper points out that in the future Suzhou should further improve the county sports lottery market with fine management as the premise, sustainable development as general principles, and market competition as the target and administrative reform as the opportunity.
\end{abstract}

\section{Keywords}

Sports Lottery, Lottery Market, Lottery Economy, County Sports Lottery Market

\section{Introduction}

Since the birth of lottery, it sweeps more than 120 countries and regions all over the world with its irresistible charm and gradually develops into a global big industry, and lottery economy continues to expand the scale. With the deepening of China's economic system reform and the improvement of the degree of marketization, the problem of the development of social public welfare is placed in front of all levels of government. Although the central and local financial departments at all levels set aside large sums of money in every financial year and input speed is almost synchronous with national economic growth rate, only relying on state funding to solve these problems has little effect due to too much debt. Therefore, in the case that the national financial investment is difficult to rapidly increase, the lottery issuance is a good policy choice to make 
up for the lack of national financial investment in social welfare undertakings [1].

According to the economic phenomenon and the characteristics of the lottery, Chinese media put forward the idea of lottery economy for the first time in 2000, which contains two levels of meaning: first is the direct economic attributes embodied in trading process and the cumulative effect of lottery trading. That means as long as people buy lottery, part of the purchase cost will become public welfare fund turned over to the state, part will become the bonus awarded to the winning lottery, and the remaining part will become publicity, distribution and other relevant work fee [2]. Therefore, the more lottery sales are, the higher the direct economic effect has. Second is the indirect economic attribute due to the emergence and development of lottery. The lottery industry belongs to the downstream industry in the industry chain. And according to the multiplier effect, the lottery industry is bound to promote the development of printing, publishing, media, and a series of relevant upstream sector and industry [3]. From the current situation of China's lottery economy, this paper focused on the development background, practical exploration and achieving results of Suzhou county sports lottery market, and pointed out its future development direction.

\section{Status Quo of Chinese Lottery Economy}

Since the start and issuance of lottery, it has raised a lot of public welfare fund which is indispensable additional funds for the development of national and local public undertakings. With the growing prosperity of the lottery market and the diversified design of lottery species more and more close to the public, the economic and social effect of lottery are more and more obvious. But compared with foreign countries, Chinese lottery economy is still in the initial stage of development, and there are obvious gaps in lottery issuance, management and other sides. From the perspective of the economic contribution of lottery sales, Italy's lottery revenues account for $1.5 \%$ of the country's fiscal revenues, America lottery sales account for $0.87 \%$ of gross domestic product, and $90 \%$ of the funds of Swiss National Sports Federation is from sports lottery.

In recent years, the development speed of Chinese lottery is increasing by about $40 \%$, far more than the average incremental level of the world's lottery industry which is as $18 \%$. And its issuance size is still expanding when actively and certainly promoting the development of other relevant industry. In accordance with the prevailing international experience, the size of a country's normal lottery sales should be more than $0.5 \%$ of its Gross Domestic Product (GDP). According to this calculation, the issuance size of Chinese lottery is up to 338.35 billion Yuan in 2015, while the actual sale of Chinese lottery is 367.88 billion Yuan. From the perspective of the number of lottery buyers in a country, they respectively account for $100 \%, 85 \%$ and $70 \%$ of the total population in Italy, America and Japan, while the proportion in China is 6\% - 7\%. Besides, the legal system construction, playing structure, management system, operation mechanism and other aspects of economic and social effects are all need to be improved.

\subsection{The Development Level of Lottery Market Is Low}

Seeing from the base of population, the per capita consumption of China's lottery is less 
than 50 Yuan, which is not only lower than the global average, but also lower than the Asian average. China's lottery sale is not in keeping with its status in the world. And the reason for this problem is as many scholar mentioned: 1) Market development efforts are not enough; 2) Per capita consumption is not high; 3) The lottery structure is not reasonable; 4) Regional distribution is not uniform, etc. Lottery buyers in China is mainly low-income people, while the wealthy class, which is the major contributor, rarely set foot in buying lottery. Furthermore, only $6 \%$ - $8 \%$ lottery buyers concentrate in the coastal developed cities. Lottery buyers in America not only occupy a higher proportion of the total population, but also come from different classes. Overall, the development of China's lottery industry is lagging behind.

\subsection{Lottery Industry Runs in Low Efficiency for Long}

Another major problem in the current development of China's lottery economy is the co-existence of the offside and absence phenomenon of lottery management, which leads to low efficiency in lottery issuance and management. The present management system in China is the Financial Department of the State Council to carry on the management of the lottery. When the instant-open lottery is popular, in order to obtain the right to issue the lottery, all regions and departments devote to spend their efforts competing for the cardinality and the scale. While the sale of computer-terminal lottery is along the way, all regions and departments are in the fight on playing variety. When no one cares how to reduce the cost of issuance, how to develop new lottery products, how to strengthen flexible management on lottery industry and other problems, it's easy to form the strange phenomenon of "strong government and weak market" finally, putting the cart before the horse. Thus, these rent-seeking costs and vicious competition in sales of lottery artificially raise the issuance cost and reduce the operating efficiency. In China, $15 \%$ of the annual lottery sales are used to cover the cost, which brings up difficulties for the long-term, steady and healthy development of lottery industry, while in foreign countries the cost of lottery sales account for $12 \%$ or less than $12 \%$ of total sales.

\subsection{People's Understanding of the Lottery Is Still at a Low Level}

Another problem along with the relatively low level of lottery industry in China is the weak understanding and bad expectation of most lottery buyers, which is closely related to the propaganda orientation of China's lottery issuance agencies and the news media. Most of the current propaganda orientation is to highlight the lottery's wealth function, even embrace for a night sudden wealth, but often ignore the correct guidance of lottery buyers', resulting in some buyers' abnormal flaunt psychology [4]. Especially some propaganda ignored the original meaning of charity and the responsibility to help the poor and the weak as a citizen behind the lottery, and avoided talking about regressive tax characteristics of lottery products. So, the pain index caused by not winning of the low-income is much greater than the rich. However, winning, after all, is a small probability event with many random and uncertainty, and even lead to the Matthew Ef- 
fect-the rich become much richer and the poor become much poorer, which differ from the original intention of the government. Especially in China the low and medium income group is the main body of the lottery market at present and they have higher expectations for winning. If the lack of proper publicity and guidance continues, the players may lose the trust of the public lottery, and part of the quick successes will turn to private lottery and gambling. The consequences will not only make the development of lottery industry lost support, but also corrupt social values and cause social instability.

\subsection{Illegal Peripheral Things Have More and More Adverse Influence on Public Lottery}

Now the transportation and communication get extremely developed, and the earth becomes smaller and smaller. With the development of foreign gaming industry, China has been surrounded by the surrounding countries of the casino. As a result, China, in which country Gambling is forbidden in the international gaming market, can only bear the social costs of the outflow of gambling capitals. At the same time, the spread of domestic underground private lottery, network gaming and mobile gaming, has a "crowding-out effect" on legitimate lottery, which seriously affect the further development of legitimate lottery [5].

\section{Background of Developing the Sports Lottery Market in Each County of Suzhou}

Suzhou began to issue sports lottery in 1988 and with the gradual expansion of the lottery issuance, Suzhou Sports Lottery Office was established in 1993 by Suzhou Sports Commission. Approved by the Office of Suzhou Municipal Organization Committee on December 16 in 1997, the Management Center of Suzhou Sports Lottery, belonging to the Management Office of Suzhou Sports Market, was established. Then in 2006, approved by the Office of Suzhou Municipal Organization Committee, the Management Center of Suzhou Sports Lottery became an independent government-affiliated institution which belongs to Suzhou Sports Bureau, fund from Government balance grant (extra-budgetary funds).

In accordance with the work plans of national and provincial Sports Lottery Center, Suzhou sports lottery issuance combined with the specific requirements of Suzhou municipal government, go in the direction of market-oriented strategy, service-based requirement and county distributed progress, to promote the rapid development of sports lottery. During the 12th Five-Year, the cumulative sales of Suzhou sports lottery is more than 18 billion, of which the county sales accounted for $67.12 \%$ (see Table 1 ) and the playing varieties meet the needs of different audiences (see Table 2). The county sports lottery issuance makes a positive contribution to the vigorous development of sports lottery in whole Suzhou.

The development of county sports lottery market is a systematic work, municipal management institutions of sports lottery need more support of superior policy and local practice and other objective conditions in addition to the subjective desire when opening 
Table 1. Suzhou county lottery revenue from 2006 to 2015 (unit: 10 thousand Yuan).

\begin{tabular}{ccccccccccc}
\hline \multirow{2}{*}{ Region } & \multicolumn{10}{c}{ Year } \\
\cline { 2 - 10 } & 2006 & 2007 & 2008 & 2009 & 2010 & 2011 & 2012 & 2013 & 2014 & 2015 \\
\hline Urban District & 19,617 & 24,892 & 33,833 & 52,906 & 86,035 & 130,551 & 142,180 & 145,476 & 156,908 & 162,735 \\
Kunshan & 5769 & 8720 & 13,622 & 20,184 & 30,823 & 47,943 & 55,067 & 57,541 & 72,199 & 64,675 \\
Changshu & 6418 & 9189 & 11,274 & 16,715 & 24,399 & 36,071 & 34,355 & 31,688 & 38,287 & 34,241 \\
Wuzhong & 5175 & 7391 & 10,520 & 16,558 & 22,157 & 32,083 & 36,307 & 34,767 & 44,372 & 47,246 \\
Zhangiiagang & 7130 & 10,862 & 11,874 & 15,819 & 20,806 & 32,041 & 32,916 & 31,500 & 36,112 & 32,022 \\
Wujiang & 4679 & 6514 & 8766 & 13,791 & 18,951 & 28,096 & 32,089 & 32,655 & 34,707 & 31,128 \\
Taicang & 2824 & 4100 & 4718 & 6374 & 8644 & 11,759 & 13,575 & 13,980 & 17,529 & 16,704 \\
Whole City & 51,613 & 71,668 & 94,607 & 142,347 & 211,815 & 318,545 & 346,488 & 347,607 & 400,113 & 388,750 \\
\hline
\end{tabular}

Data sources: sales report of the Management Center of Suzhou Sports Lottery.

Table 2. Lottery sales in different regions under different playing varieties in 2015 (unit: 10 thousand Yuan).

\begin{tabular}{cccccc}
\hline \multirow{2}{*}{ Region } & Total Sales & \multicolumn{4}{c}{ Different Playing Variety } \\
\cline { 3 - 6 } & & Traditional Play & High-Frequency Game & Instant-Open & Contestable-Surmise \\
\hline Urban District & 162,735 & 29,297 & 46,225 & 16,702 & 70,512 \\
Kunshan & 64,675 & 13,380 & 30,649 & 7690 & 12,957 \\
Changshu & 34,241 & 9254 & 10,692 & 3958 & 10,337 \\
Wuzhong & 47,246 & 8645 & 15,253 & 4857 & 18,491 \\
Zhangjiagang & 32,022 & 8908 & 10,211 & 2491 & 10,412 \\
Wujiang & 31,128 & 8501 & 10,059 & 3482 & 9084 \\
Taicang & 16,704 & 4600 & 5065 & 1289 & 5750 \\
Whole City & 388,750 & 82,585 & 128,153 & 40,469 & 137,542 \\
\hline
\end{tabular}

Data sources: sales report of the Management Center of Suzhou Sports Lottery.

the county market. Suzhou vigorously develops the county sports lottery market is mainly due to the following three aspects:

\subsection{Policy Guidance Function}

Jiangsu Sports Bureau formulated the Work Assessment Criteria and Methods of County Sports in Jiangsu Province in 2004, which took sports lottery issuance index, including total ranking of sports lottery sales, growth rate ranking of sports lottery sales and so on, into the evaluation scope of county sports development, and reflected the importance of sports lottery issuance to the development of sports undertakings. In February 2006, Jiangsu Sports Work Conference further emphasized the sports lottery work is the number one project. Because of the policy guidance and leadership attention, the understanding of the importance of sports lottery has improved by sports de- 
partment at the county level, which has become a prerequisite for the development of the county sports lottery market.

\subsection{Internal Organizational Construction}

Sports departments at all levels are the sports lottery issuance authorities, whose nature and function are also related to the quality of the lottery issuance work. Every county sports department in Suzhou is an independent organizational system, which is specialized in sports function departments, and this pattern makes the line management more fluid. On the other hand, this also means that sports departments at all levels will pay more attention to the sports lottery work. Therefore, establishing and improving professional sports department is a solid organization foundation for developing county sports lottery market.

\subsection{County Economic Conditions}

The rapid development of Suzhou's economy, especially the development of county economy, has laid a solid foundation for the development of sports lottery in recent years. From the First Selection of Chinese Top 100 Counties (County-Level Cities) for Basic Competitiveness of County Economy in 2001 to now, every county or city under the jurisdiction of Suzhou municipal government has been maintained in the country's leading position. Zhangjiagang city, Changshu city, Kunshan city, Taicang city, Wujiang district and Wuzhong district are all the reputation for the county economy. It should be noted that Zhangjiagang city, Changshu city, Kunshan city and Taicang city are of the top 10 counties in the whole country for the powerful economic strength and the whole county economy account for more than half of the Suzhou economic aggregate. It is based on the vigorous development of county economy in Suzhou that makes it possible to develop the county sports lottery market.

\section{Practice Exploration on the Development of Sports Lottery Market in Suzhou}

During the 12th Five-Year, under the guidance of the Suzhou Sports Bureau, Suzhou Sports Lottery Center starts from the construction of system mechanism, talent team, sales channel, market brand and so on, and gradually developed and improved the county sports lottery market.

\subsection{Improve Management Level Steadily by Refining System and Reforming Mechanism}

Suzhou Sports Lottery Center further intensifies the efforts of the system construction by abolishing, amending or supplementing the original system while implementing the lottery management regulations as an opportunity, and injects new vigor and vitality for the lottery system building. Standardized, institutionalized, programmed and formalized level of sports lottery management gets promoted by actively exploring and trying to establish the management mechanism for the operation of sports lottery mar- 
ket, improving the target responsibility system of specialized administrative personnel and the evaluation system of the star sales outlets, gradually establishing a scientific and effective incentive mechanism and supervision mechanism. In a word, Suzhou realized the collaborative development of urban district and corresponding county, and promoted the lottery sales of the two places to develop in depth.

\subsection{Enrich Talent Team by Strengthen the Training and Shaping the Morals}

Suzhou attached importance to talent team construction by compiling the Specialized Management Personnel Handbook, carrying out various forms of training, and actively organizing preaching contest, and finally achieved good results. Suzhou also printed and distributed 100 Questions for Lottery Salesmen, organized service skill competitions, arranged them to participate in the distance learning organized by the State General Sports Administration. To branch salesmen, Suzhou took on pre-job training, special training and multi-level business training. During the 12th Five-Year, there are cumulative trainings for salesmen nearly 2000 sessions.

\subsection{Propel Standardized Sales Solidly by Ensuring Safety and Improving Facilities}

Suzhou ensured safety as a hard task, constantly enhanced consciousness responsibility and crisis consciousness, and improved the risk prevention and control system. With regard to preventive work, Suzhou organized the staff to hold fire safety drill and other training regularly. With regard to marketing propaganda, Suzhou strengthened the management and training of sales outlets, and set the warning signs to guide the lottery rational purchase and against market risks at the same time [6]. With regard to hardware facilities of lottery outlets, Suzhou installed cameras, fire extinguishers and other equipments to ensure security operation.

\subsection{Uplift Quantity and Quality of Sales Outlets by Unifying Image and Extending Scale}

Sales outlets construction is an important foundation for market development and market management. During the 12th Five-Year, the number of lottery sales outlets in Suzhou got a rapid growth, and the construction of sales outlets changed from scale expansion to the overall planning layout and standardized management. For example, Suzhou actively developed the rural and township market to fill the market gaps, actively explored and standardized the development of direct sales centers and self-service sales terminals to expand the new sales channels. With the piecemeal implementation of the standardized construction and classified management, the internal environment and the external image of sales outlets has been greatly improved. Through system perfection, training reinforcement, incentives after assessment, experience exchange, skills competition and other ways, sales ability and personnel quality of sales outlets have significantly improved. 


\subsection{Impress the Public Deeply with Lottery Image by Expanding Publicity and Spreading Brand}

Suzhou particularly focused on propaganda work and steadily broadened the channels of publicity. At present, the mainstream media, such as television, newspaper, broadcast, and network, have been covered in Suzhou. For example, lottery winning news was reported in the people's livelihood news columns daily, Gusu Evening Newspaper and Suzhou Commercial Newspaper published a special edition of Sports Lottery weekly, relevant information real-timely was propagated or reported in Famous Suzhou, Suzhou News Network, Suzhou Hotline and other network media. Furthermore, Suzhou founded Suzhou lottery monthly showing the achievements of Suzhou sports lottery in every aspect, and got the recognition and support of lottery buyers, salesmen and employees. In addition, Micro-blog and WeChat public number certificated by the real name of the Management Center of Suzhou Sports Lottery have been applied successively, and through updating and maintaining by specially-assigned persons, they became new platforms to listen to the voice of internet users and to achieve real-time interaction.

\section{Thinking on the Development of the Sports Lottery Market in the County of Suzhou}

The development of the county sports lottery in Suzhou has achieved some results, whose case not only reflects the new ideas for the development of sports lottery industry, but also reflects the ability of administrative organizations to adapt to social changes. In order to better develop the county sports lottery market in Suzhou, the followings should be done:

\subsection{Take Fine Management as the Premise}

At present, the number of sales outlets in each county of Suzhou ranges from 150 to 300. In accordance with the existing sales outlets layout of sports lottery, every county is basically in a relatively saturated state. In view of this situation, the original strategy of Distributing Outlets and Increasing Capacity is not adapt to the new development needs, while filling in the blanks is the work emphasis of the sports lottery distribution for a long time in the future. In addition, the municipal and county-level management agencies of sports lottery have no authority and strength to add new play ways to promote the growth of regional sales. So, it is the best choice that through the fine management to develop the sports lottery market. To Suzhou, perfect county management agencies and professional management team make it possible to fine management. Together with standardized sales outlets, Suzhou makes efforts to improve the quality of a single network, thereby expanding the size of the sales.

\subsection{Take Sustainable Development as General Principles}

Since Suzhou sports lottery has achieved rapid development during the 12th Five-Year, how to keep the scientific development at the high starting point is an important issue 
to be studied and solved. From the analysis of sales data in the past two years, all counties of Suzhou occupied about $75 \%$ of the whole city's sports lottery terminals, but only achieved sales volume of $67.12 \%$, thereby narrowing the gap between these two ratios is the direction of future efforts. The county market in Suzhou is full of energy and potential, whether it is the size of the economy or the number of population that provides a considerable space for the development of the county sports lottery. Only by focusing on methods, seizing the key, devoting particular care to precision and striving to achieve the quality of the single machine in the development of the county sports lottery market, can Suzhou break the bottleneck of restrictions for sports lottery in the future.

\subsection{Take Market Competition as the Target}

During the time of transferring development mode and adjusting economy structure nation-widely, sports lottery economy is also facing unprecedented challenges and pressures, and how to turn challenges into opportunities and turn pressure into motivation is the problem that sports lottery managers must consider about. Suzhou sports lottery is in the rhythm of rapid development, but also under the pressure from the welfare lottery at the same time. In spite of a slight advantage for sports lottery compared with welfare lottery in the market competition, it will be overtaken by any carelessness, which is also the same in the county market competition. Therefore, the development of the county sports lottery market must take market competition as the goal. The practice of the development of sports lottery in Suzhou has proved that strong city comes from strong county. During the 13th Five-Year, Suzhou need to further focus on upgrading in the original basis by increasing sales volume and enhancing the influence while adhering to the public welfare nature of sports lottery [7].

\subsection{Taking the Reform of Administrative Organization as an Opportunity}

The government controls a large number of resources, although in a certain period it can promote economic development, there are still many deficiencies which are not adapted to the economic development. So, the construction of service-oriented government has become inevitable in the context of power decentralization, which is also an important reason for increasing sales of county sports lottery in Suzhou. In order to promote the lottery industry into the market, weaken the administrative intervention, and reduce the possibility of rent-seeking in the lottery industry, Suzhou Sports Bureau supervises and guides the development of the lottery industry according to the principles of market economy. Suzhou Sports Bureau not only makes continuous reform of its own institutions, but also pays attention to improve their learning ability, to build a learning organization and to improve the ability to adapt to society. In addition, Suzhou Sports Bureau popularizes the sports lottery through the study and use of new media communication, and improves employee quality by encouraging organization members to learn. 


\section{References}

[1] Wu, Y.S. (2000) The Economic Analysis on Lottery. Journal of Hebei University of Economics and Trade, 6, 17-22.

[2] Li, H. and Ding, Y.J. (2001) On Study of Comparision between Our Country and Developed Countries in Sports Lottery Tickets Industry. Journal of Xi an Institute of Physical Education, 1, 14-16.

[3] Xiong, P. (2003) Rational Thinking on the Development of "Lottery Economy" in China. Contemporary Finance \& Economics, 2,108-110.

[4] Liu, C.L. and Shi, J.J. (2000) Research on the Misunderstanding of Lottery Tickets. Consumer Economics, 5, 62-63.

[5] Li, B.Q. and Hou, H.J. (2000) Preliminary Study on the Legal Regulation of Lottery Industry in China. Academic Forum, 2, 65-68.

[6] Hu, S.H. and Wu, Z.X. (2012) Influence of Brand Personality Perception of Sports Lottery on Intention of Buying Sports Lottery-Taking Guangdong Province as an Example. China Sport Science, 6, 25-32.

[7] Li, Y. (2008) Comparative Research on Sport Lottery Regulations in China and Foreign Countries. Journal of Wuhan Institute of Physical Education, 2, 39-44.

\section{Submit or recommend next manuscript to SCIRP and we will provide best service} for you:

Accepting pre-submission inquiries through Email, Facebook, LinkedIn, Twitter, etc.

A wide selection of journals (inclusive of 9 subjects, more than 200 journals)

Providing 24-hour high-quality service

User-friendly online submission system

Fair and swift peer-review system

Efficient typesetting and proofreading procedure

Display of the result of downloads and visits, as well as the number of cited articles

Maximum dissemination of your research work

Submit your manuscript at: http://papersubmission.scirp.org/ 